\title{
Monitoring of Rail Corrugation Growth on Sharp Curves For Track Maintenance Prioritisation
}

\author{
Sakdirat Kaewunruen \\ School of Engineering, The University of Birmingham, B15 2TT UK.
}

(Received 3 May 2015; accepted 1 March 2017)

This paper presents the utilisation of dynamic wheel/rail interaction to monitor rail corrugation growth already detected on sharp curved tracks, in order to prioritise track maintenance. In general, a railway network generally spans over a large distance, so the structural health monitoring of such a rail infrastructure system is one of the grand challenges in rail industry practice. Especially in an underground or subway system, the facilities, resources, and time period permitted for critical infrastructure inspection and maintenance is considerably limited. As a result, the utilisation and application of any inspection train vehicle has been more demanding than ever. A rail corrugation defect is the periodic, undulated or wave-like vertical alignment of rail surface. Corrugations are typically caused by uneven wears due to the variations of wheel-rail contact stresses. The wavelength and severity of rail corrugations is dependent on track structure, track geometry, traction system, rail vehicle behaviours, and wheel-rail interaction. The rail corrugations are the source of rapid track degradation, poor ride comfort, and nuisance noise. Often, such rail irregularities are initially observed and detected by train drivers and engine ride inspectors. To enable predictive maintenance, a set of rail surface data of a very sharp curve was chosen for demonstration of rail corrugation monitoring by integrating numerical train/track simulations, axle box acceleration data obtained from the calibrated track inspection vehicle "AK Car", and spectral data analytics.

\section{INTRODUCTION}

Social and economic growth of a city, region or country is inevitably underpinned by rail mass transit. To stimulate sustainable productivity, an urban rail infrastructure is often built either underground or on the surface, surrounded by agglomerate buildings and public communities. Its network generally spans over a large distance. Ongoing operation and maintenance of rail infrastructure systems are critical to public safety, in addition to the routine management of business risks and reliability. With a significant demand from the public to cater faster and more frequent train services (evidenced by the 24/7 railways such as in London, Berlin, Sao Paolo, and many more to come), structural health monitoring of such rail infrastructure systems is one of the grand challenges in practice. Especially in underground train or subway systems, track engineers commonly envisage the facts that the tunnel facilities, resources, and time windows permitted for railway staff to carry out the critical infrastructure inspection and maintenance is, indeed, extremely limited. On the other hand, any tiny period of train-free duration (e.g. 3 hours in Tokyo; 1-2 hours in Hong Kong; or down to 5 minutes in London) in a late night rather discourages on- track activities by the railway staff. This is due to the difficulties and the deficiency of time and access to facilities to carry out any meaningful inspection and maintenance tasks. As a result, the utilisation and application of an inspection train vehicle has been more demanding than ever. ${ }^{11,12,17}$

Rail corrugation is an irregularity on rail running surface, inducing large dynamic loadsand vibrations onto adjacent railway track components as well as rolling stocks. Such a defect is a periodic, undulated or wave-like vertical alignment of the rail surface. The rail corrugations are typically caused by uneven wears, due to the variations of wheel-rail contact stresses. The wavelength and severity of corrugations is dependent on track structure, track geometry, traction system, rail vehicle be- haviours, and wheel-rail interaction. The rail corrugations are the source of rapid track degradation, poor ride comfort, excessive vibration, and noticeably nuisance noise. Often such irregularities can be observed on the low rail of small-radius curves. A large number of research studies have been devoted into the fundamental causes and mitigation techniques. ${ }^{6,21,29,30}$ The effect of rail corrugation wavelengths on noise generations has been the main focus in most studies. It is noted that $v=f \lambda$ ( $v$ is the train speed, $f$ is the frequency, and $\lambda$ is the wavelength). "Contact patch filter" has been found to be a mechanism that attenuates very high frequency effects above $2 \mathrm{kHz}$. Table 1 shows the frequency ranges associated with railway noises due to rail corrugations. To meet appropriate requirements of rail authority, maintenance and control of rail roughness at various wavelengths are generally carried out by rail grinding and lubrication methods, depending on various factors such as geometry, location, gradient, environments, etc..$^{2,7,14,29}$ In Australia, an urban rail network suffers from rail corrugations on the low rail in curves. Such defects often regenerate secondary ground-borne vibrations in surrounding environments, such as nearby buildings and structures. In addition to noise issues, the defects incur costly track and train maintenance because the excessive vibrations from wheel/rail interaction undermine structural integrity of those railway assets. ${ }^{21,22}$ It is important to note that the rail corrugations could also be a source causing other types of rail defects, e.g. rail squats, shelling, etc. ${ }^{3,15,18}$ On this ground, monitoring and control of rail corrugations is mandatorily required in practice. ${ }^{19,31,32}$ It is, therefore, very important to develop an alternative monitoring methodology that could be practically applied to special railway tracks with restrictions of safe access and facilities.

The inspection or patrol train vehicle is generally equipped with sensors (i.e. accelerometers, gyroscope, ground penetrating radar, laser profiling, etc.) and high-speed cameras to 
Table 1. Wavelength ranges associated with railway noises. ${ }^{6}$

\begin{tabular}{||c|c|c||}
\hline Railway noise & Frequency ranges & Wavelength $($ at $40 \mathrm{~km} / \mathrm{h})$ \\
\hline Audible ground-bourne & $25-250 \mathrm{~Hz}$ & $40-400 \mathrm{~mm}$ \\
\hline Structure-bourne & $100-2000 \mathrm{~Hz}$ & $5-100 \mathrm{~mm}$ \\
\hline Wheel-rail rolling noise & $100-5000 \mathrm{~Hz}$ & $2-100 \mathrm{~mm}$ \\
\hline Range of greatest human sensitivity & $2-5 \mathrm{kHz}$ & $1-5 \mathrm{~mm}$ \\
\hline
\end{tabular}

supplement track inspection activities. This paper presents the utilisation of an inspection train vehicle to evaluate and monitor rail corrugation growth on curved tracks. It aims to provide an alternative on-board monitoring approach for helping track engineers in maintenance activity prioritisation. It highlights the integration of numerical train/track simulations, axle box acceleration data obtained from the calibrated track inspection vehicle "AK Car", and data analytics in order to assess and monitor rail corrugation growth on curves. A case study is presented to demonstrate practical evidence and examine the technique to on-board monitor the rail corrugation defects on a sharp curve, where short-pitch rail corrugation on the low rail prevails. 4, 8,25,26 The emphasis of the case study is placed on an Australian underground rail track system, where it is extremely difficult to reach for routine inspections by detailed walking method or by using any mobile handheld equipment (such as CAT trolley, laser board for roughness measurement, or roller wheel for surface profiling, etc.).

\section{TRACK INSPECTION VEHICLE}

Track recording data is the track geometry data obtained from an inspection vehicle. The accuracy, repeatability, and quality of the data depend largely on measurement method, sensor and instrumentation, train speed, and location identification. ${ }^{20}$ Figure (1) shows the AK Car and its analytical modelling. In this case study, the track inspection vehicle has been installed with axle-box accelerometers. The inertia data is then computed to provide track maintenance engineers with geometry data. Figure (2) shows the flowchart to derive geometrical data. ${ }^{27}$ In practice, the wheel has been retrofired frequently to remove any potential of irregularity over time. Wheel roughness has been monitored from vibration records over long distance and an adaptive frequency band filtering approach (similarly to adaptive noise cancellation method) has been applied to minimize any effect from wheel roughness and any irregularity. Inertia geometry calculation method, using the trapezoidal method, has been adopted and the method has been validated by field measurements and systems tests. ${ }^{28}$ The geometry data, which had been recorded using "AK Car" Geometry Recording Vehicle, illustrates fundamental dynamic track parameters (top, line, gauge, cross level and twist) in each stage of rail track's life cycle.

\subsection{Gauge}

Track gauge is defined as the distance between the gauge points on the face of each rail. The default gauge point is $16 \mathrm{~mm}$ from the azimuth (maximum $y$ point) on the rail surface. AK Car recognises the known distance between laser cameras instrumented on its bogie, so that the resulting gauge measurement is the difference between the optimal gauge and the measured gauge. ${ }^{20}$ The standard rail gauge for the track in this study is $1435 \mathrm{~mm}$ with $600 \mathrm{~mm}$ sleeper spacing.

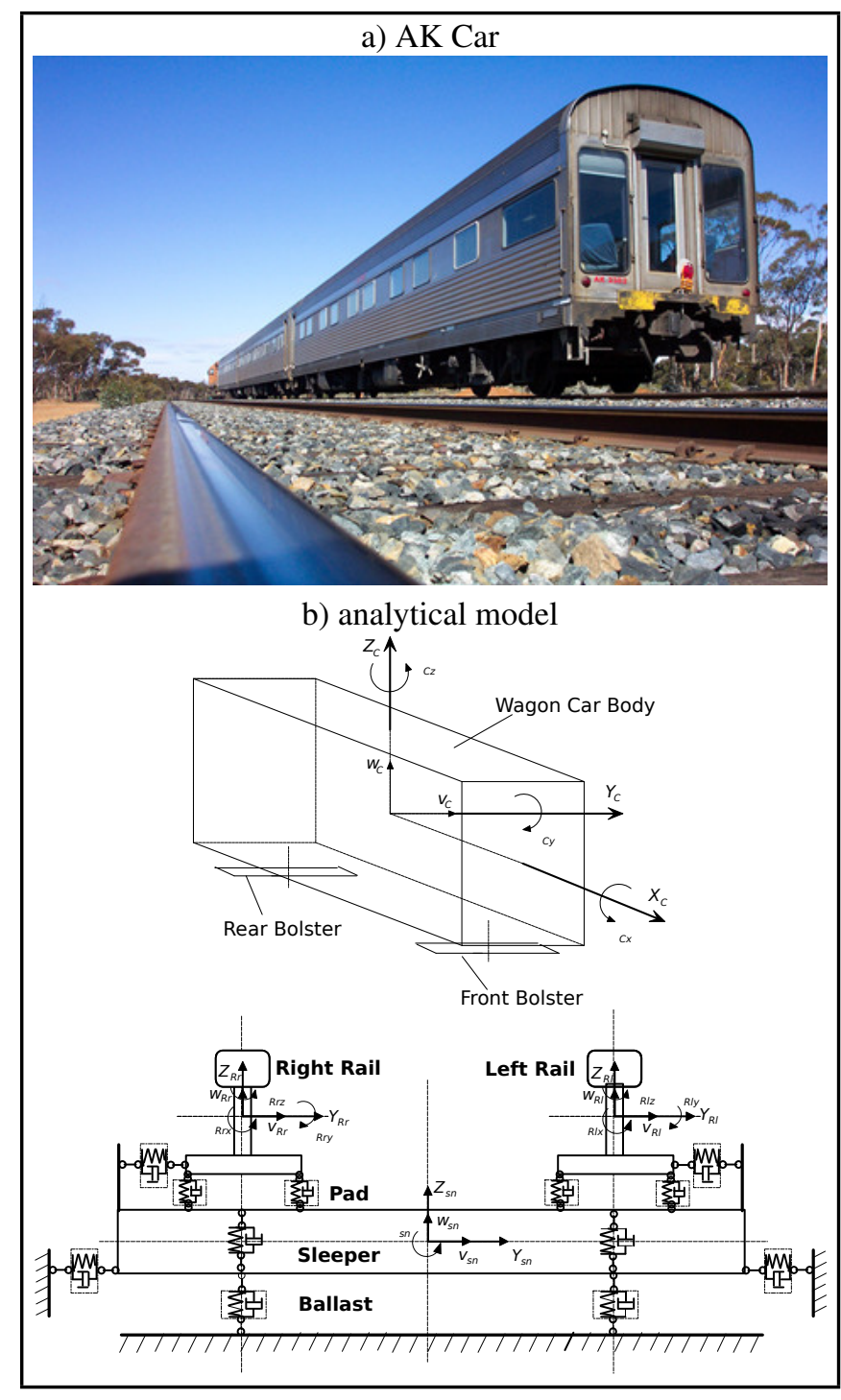

Figure 1. AK Car, a track inspection train. ${ }^{27}$

\subsection{Superelevation}

Superelevation (or so-called crosslevel) is defined as the height of one rail above the other. The superelevation is calculated from all four of the inertial measurement package components installed on the AK Car body, consisting of two single-axis fibre optic rate gyroscopes (measuring roll and yaw in terms of turning angles); two accelerometers (measuring vertical and lateral accelerations); and a signal conditioning board. ${ }^{20}$

\subsection{Top}

Track surface is defined as the evenness or uniformity of track in short distances measured along the top of the rails. Under load of the AK Car body, top surface of rails and vertical alignments can be measured by either a mid-chord offset or by a space curve method. In Australia, the AK Car uses the former method (calculating a versine at $1.8 \mathrm{~m}$ ) by adopting 


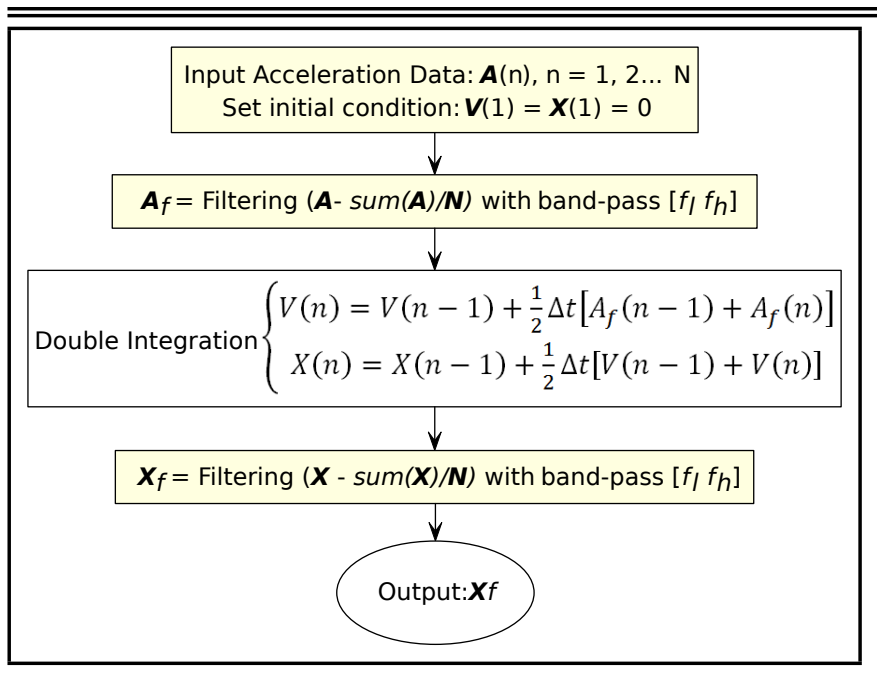

Figure 2. Inertia geometry calculation method using trapezoidal method. ${ }^{27}$ $A(i)$ is acceleration, $V(i)$ is velocity and $X(i)$ is displacement.

10 m chords. ${ }^{20}$ This has been adopted in practice to benchmark the vertical surface smoothness of railway tracks.

\subsection{Line}

Line or horizontal alignment smoothness is defined as the local variation in curvature of each rail of track. It should be zero on a tangent or straight track so that the AK Car"measured line data" represents the deviation from zero. In a curve, the deviation will be calculated from the uniform curve trajectory or design alignment over a specified distance. In Australia, the $10 \mathrm{~m}$ chord has been adopted for the purpose of benchmarking. ${ }^{20}$

\subsection{Axle Box Acceleration}

Corrugation roughness data can also be obtained by double integration of axle box accelerations (ABA) with respect to train/track receptance and signal filtering, similar to Top data. Calibration and repeatability tests were previously carried out to meet rail authority requirements. ${ }^{20,23,24}$ The wheelset receptances have been used for the calibration of multi-body dynamics. The ABA-based roughness has been validated by and in very good agreement with field roughness measurements using a laser board scanner. ${ }^{28}$ In this study, the roughness data represents the combined vertical rail surface quality for all wavelengths.

\section{CASE STUDY}

Rail corrugations have been a problem, especially in curved tracks, especially within the underground railway network. A pilot study was carried out on an urban rail network, where it is extremely difficult to access for inspection and maintenance. At the location of interest, the headway (the time gap between trains) is 2.5 minutes and the daily track possession (no train service) is about 3 hours (from 1 a.m. to 4 a.m.). This implies that any meaningful inspection (e.g. roughness measurement using laser board scanner or even CAT trolley) will incur penalty (additional track downtime due to the compulsory requirement for extra time, resources and safety-related facilities). The geometry and speed of the uni-directional track of interest are shown in Fig. (3). From Fig. (3), the section from $\mathrm{km} 0.400$ to $\mathrm{km} 0.800$ tends to undergo "unbalanced" speed that usually causes "short- pitch" low rail corrugation, compared with the adjacent section ( $\mathrm{km} 0.750$ to $\mathrm{km} \mathrm{1.055).}$ At unbalanced speed, the train travels at the speed that induces centripetal resultant force. Subsequently, the wheels acting on the lower rail will carry more weight or load burden than those on the outer rail. With additional dynamic and curving effects imposed by wheel-rail interaction, the rail will suffer from excessive cyclic wheel loads and wear out. At this location, the track structure consists of $60 \mathrm{~kg}$ rail, fastening system, and timber sleepers, embedded into concrete slab, as shown in Fig. (4). Asset inspections for this track section are often carried out in practice by using a combination of methods such as Engine Ride Inspection, train driver report, as well as a Track Inspection Vehicle, i.e. "AK Car", as shown in Fig. (1). Most rail corrugations have been often detected firstly by Engine Ride Inspection when experienced track engineers or staff can observe and identify mild corrugations through visualisation and train motions. Then, they could prioritise work, based on criticality and severity of defects, to suit their Base Operating Conditions. However, high turnaround of staff could lead to inconsistency in track maintenance prioritisation. It is, thus, important to adopt AK Car data for helping such tasks.

To evaluate and monitor the rail corrugation growth on curves for this case study, the axle box acceleration and corrugation data were collected from AK Car archives for the runs between July 2010 and August 2013. It is noted that the data sampling rate is $10 \mathrm{kHz}$, resulting in good quality data for frequency analysis up to $5 \mathrm{kHz}$, which is wellabove the wavelengths of interest (see Table 1). Figure (5) shows the raw data derived from the corrugation data archive. These data represent 'combined' track and rail roughness measured based on AK Car parameters. Note that these data have already been filtered out to minimize wheel noise in high frequency range. ${ }^{28}$ Also, using the smaller cord length filtering (e.g. $500 \mathrm{~mm}$ cord), the track deflection effect is minimal and negligible.

Based on Fig. (5), although it is difficult to measure track surface quality due to the transient nature of vibrations, it could be observed that low rail (or Top Left/TopL) tends to be much more cyclical than high rail (TopR) data. The "RMS amplitude" can generally inform the growth of roughness of track. The higher the roughness; then, rail running surface control is required (i.e. rail grinding, top of rail lubrication using friction modifier). In this case, noticeably, the RMS amplitude has decreased over the time as the rail is worn out by running wheels. But, the real question is that can rail or track engineers observe if there is a clearer growth of rail corrugation? It is unclear at this initial stage if any corrugation could be detected merely from RMS amplitudes, since the overall RMS amplitudes decrease. For most cases, the data analyses of time-domain RMS amplitude can be time-consuming and such ambiguous data could lead to uncertainties. To evaluate rail corrugation growth from these data, further analyses are thus required. Wavelength analysis is necessary to ensure that correct rail surface irregularity is emphasised. The rail corrugation defect on sharp curves tends to be frequently associated with the wavelength bands from $30 \mathrm{~mm}$ to $100 \mathrm{~mm}$. In general, the rail roughness (obtained from CAT measurement tool) can be plotted against the logarithm of wavelength (mm). Equation (1) shows the calculation method for decibel RMS of roughness amplitude $(R)$. The decibel RMS of roughness amplitude is based on the 


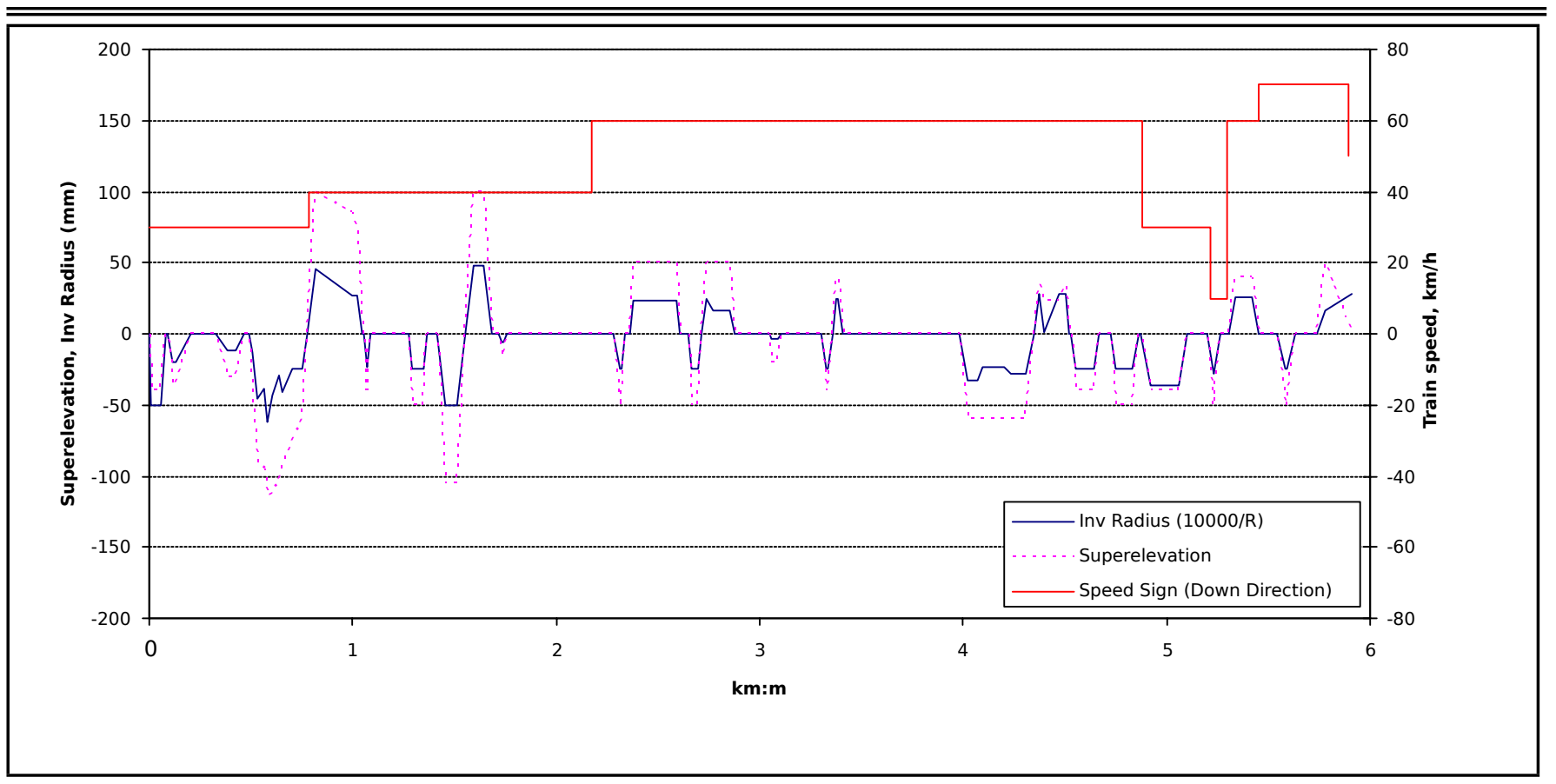

Figure 3. Track speed and geometry.

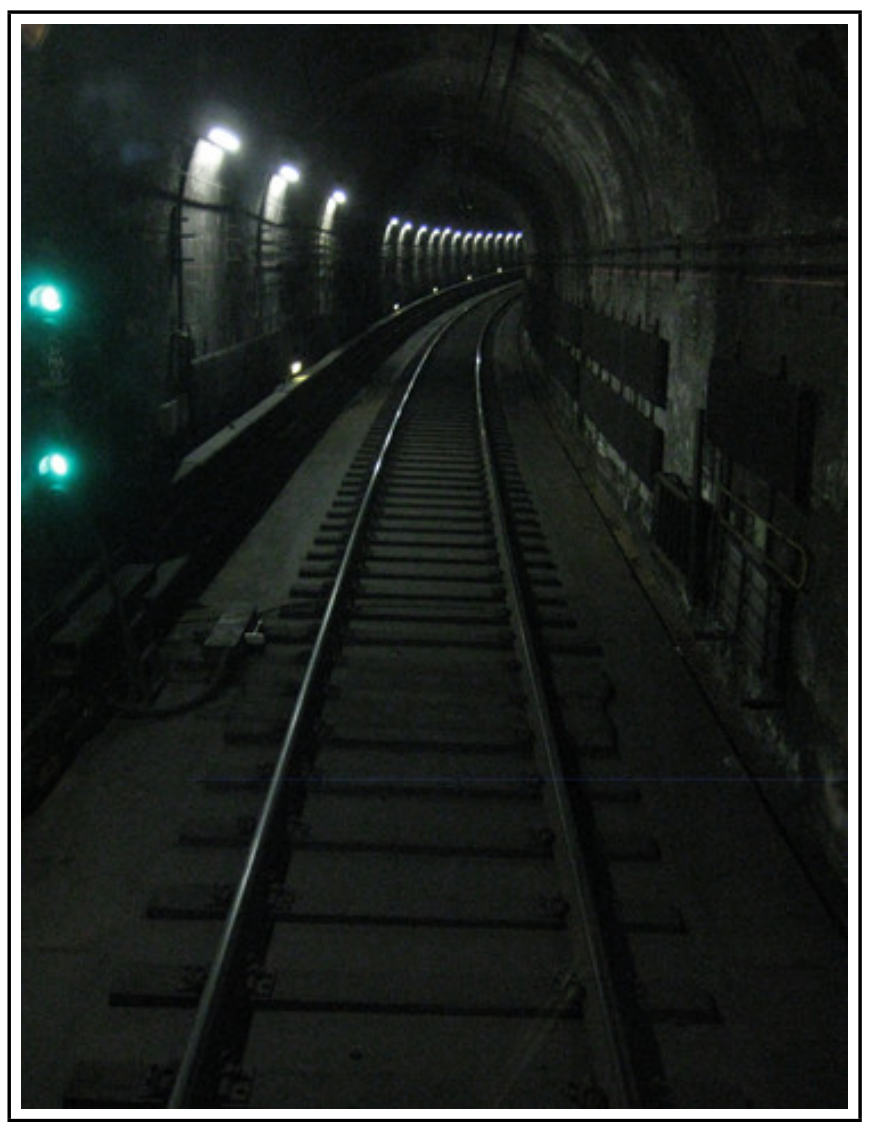

Figure 4. A typical curved track where a high-pitch corrugation on low rail tends to occur.

measured rail roughness $(r)$ :

$$
R=20 \log _{10}\left[\frac{r}{r_{0}}\right]
$$

where the referenec $r_{0}=1$ micron $(=0.001 \mathrm{~mm})$.

By the similar manner, the rail roughness obtained from AK Car corrugation data $(r)$ can also be evaluated against logarithm of wavelength $(\mathrm{mm})$.
Figures (6) and (7) show the roughness level using Top 500 and Top 1000 (Top 500: a filtered displacement between $0.25 \mathrm{~m}$ and $0.5 \mathrm{~m}$; and, Top 1000: a filtered displacement between 0.5 and $1.0 \mathrm{~m}$ ). These parameters have been chosen because they well correspond to sharp curve corrugations in this study (as also identified by Table 1). It is clear that rail corrugation exists at the wavelength band between $30 \mathrm{~mm}$ to $100 \mathrm{~mm}$ $(0.03 \mathrm{~m}$ to $0.1 \mathrm{~m})$. To monitor the rail corrugation growth, the data is re-plotted to evaluate the movement of roughness overtime with respect to ISO3095 guidelines. Note that this guideline is generally advisory, and it does not imply obligation for track maintenance. Figures (8) and (9) clearly show that rail corrugation growth on low rail is evident over time. Rail or track engineers could also notice that high-rail wavelike irregularity also grows with a slower rate compared to that of the low rail. On this basis, it is evident that it is feasible to determine the growth rate of rail corrugation over a timeframe or per million gross tonnages (MGTs) of revenue services. It is, thus, recommended for maintenance practice that filtered RMS data be used for rail corrugation defect evaluation and monitoring. However, it is noted that the track maintenance limits based on RMS data depend largely on operational requirements. ${ }^{1,5,13,16}$

For example, for asset damage control, track engineers may consider peak to peak roughness as: ${ }^{1}$ mild corrugation $>300$ microns; moderate corrugation $>500$ microns; and significant corrugation $>2000$ microns. For a noise control, ${ }^{5}$ track engineers may consider that Top 500 RMS should be less than 50 microns or $5 \mathrm{~mm} / 100$; or Top 1000 RMS may be limited by 100 microns or $10 \mathrm{~mm} / 100$. In principle, if a track section has the Top RMS exceeding a bespoke limit, rail engineers or staff should closely monitor and inspect for any structural damage of assets or for excessive nuisance noise. Based on this pilot study, rail engineers can make use of this data to efficiently plan for rail grinding or asset control strategy. 9,10 Table 2 shows the risk profile of track maintenance priority for rail corrugations. Using this monitoring technique in combina- 


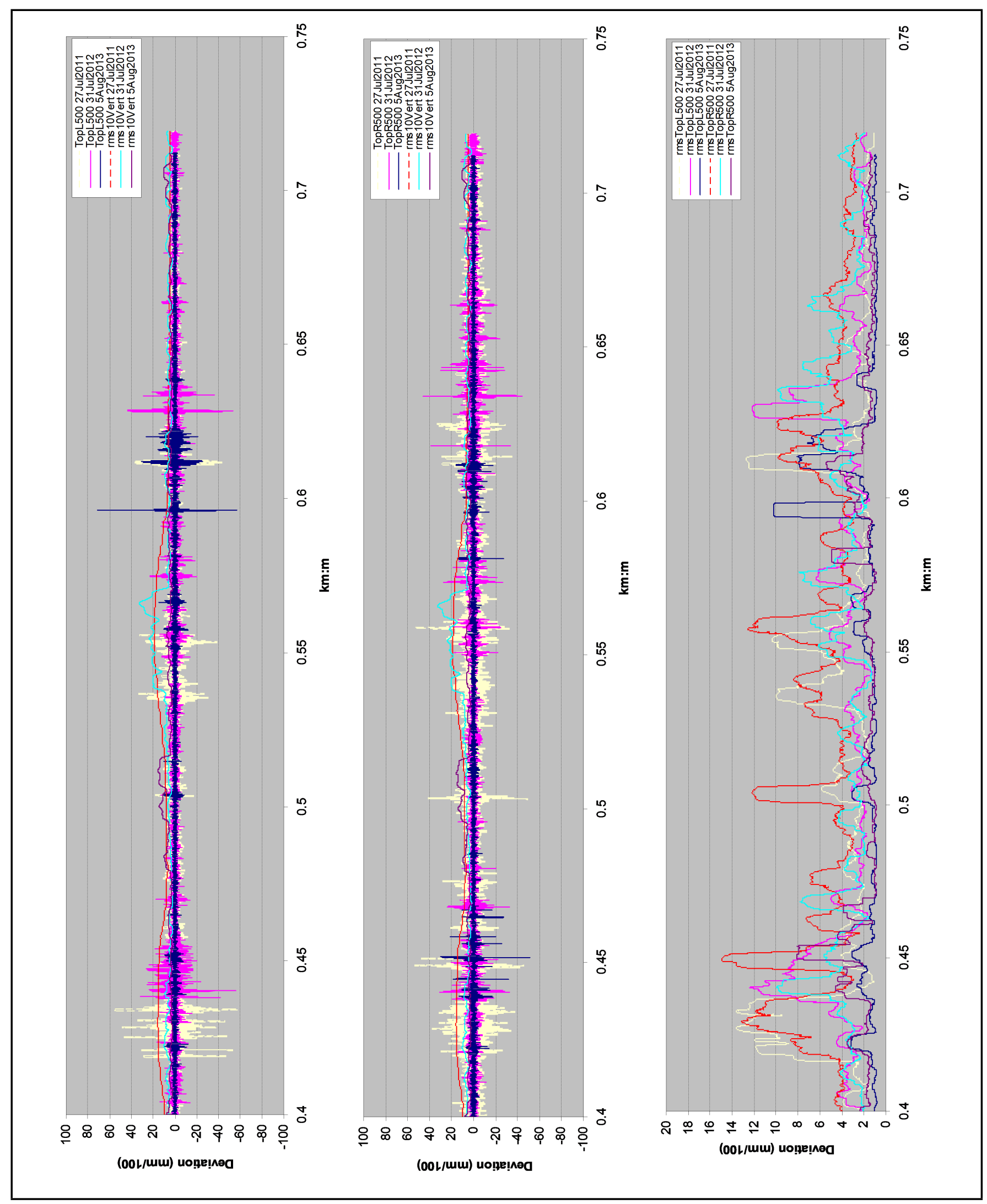

Figure 5. Corrugation growth from $\mathrm{km0.400} \mathrm{to} \mathrm{km0.800} \mathrm{(Top} \mathrm{500).}$ 
a)

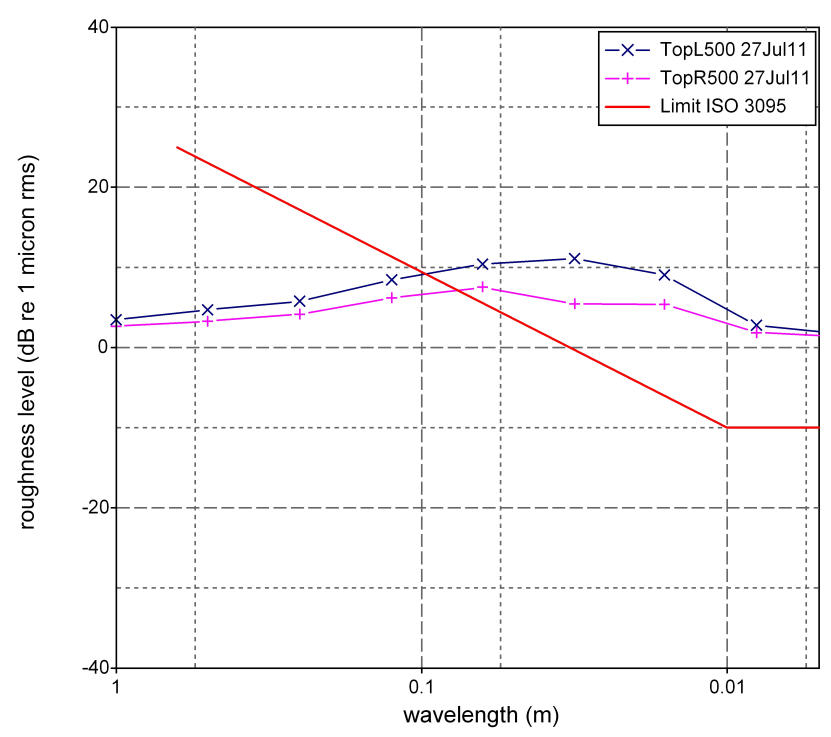

b)

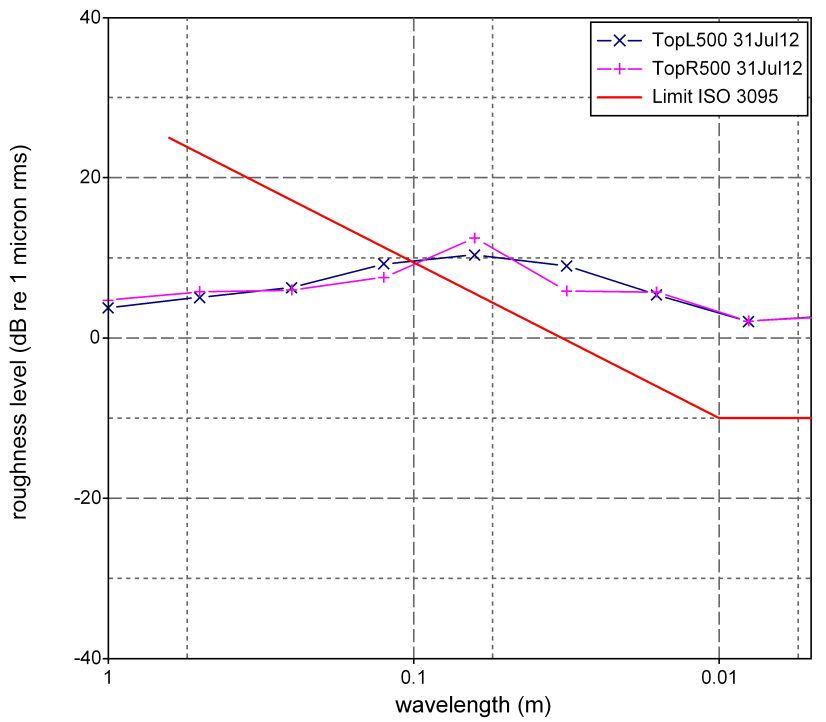

c)

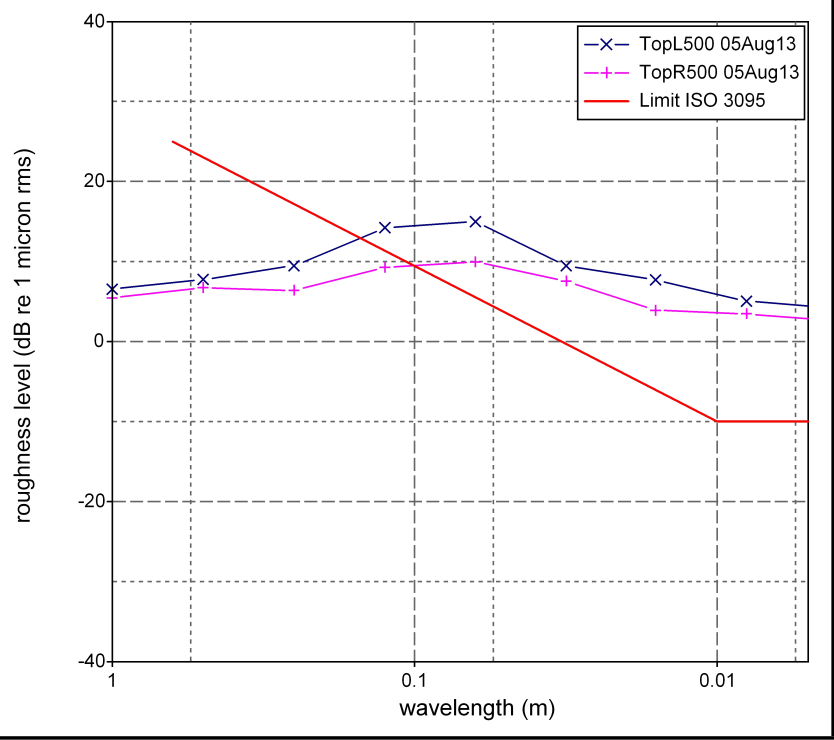

Figure 6. Roughness level using Top500 data (TopL — low rail; TopR — high rail).

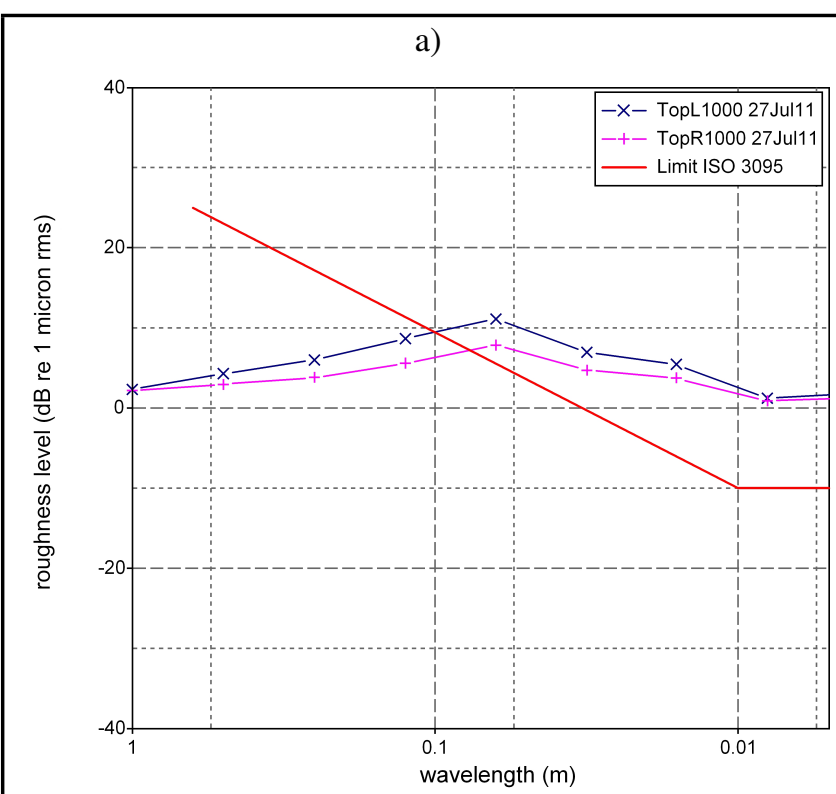

b)

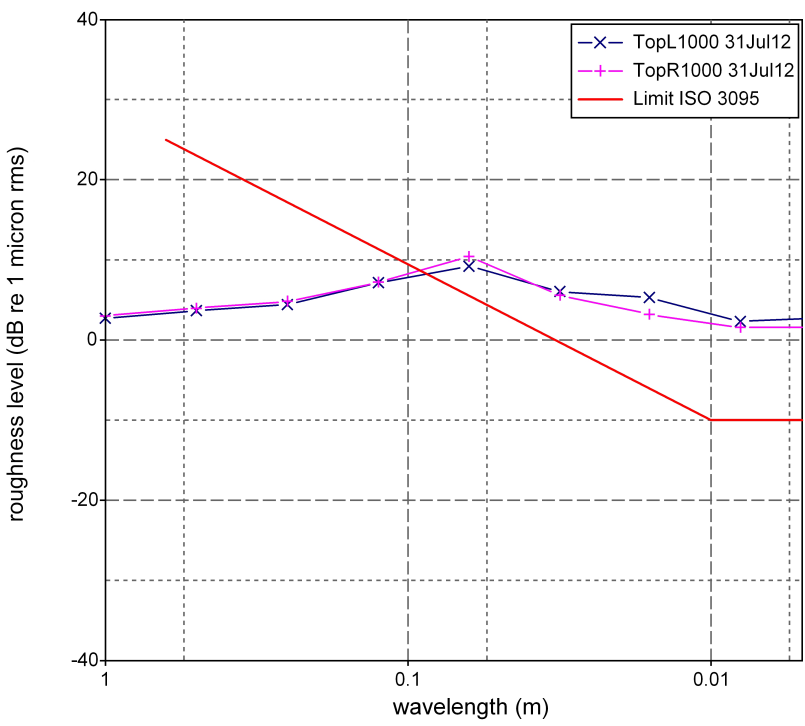

c)

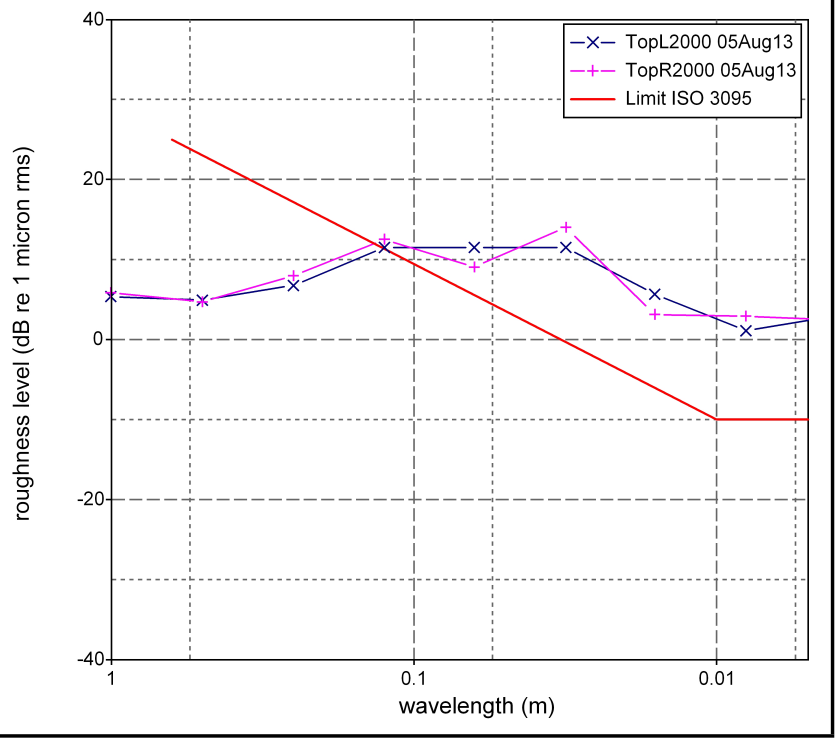

Figure 7. Roughness level using Top500 data (TopL — low rail; TopR — high rail). 


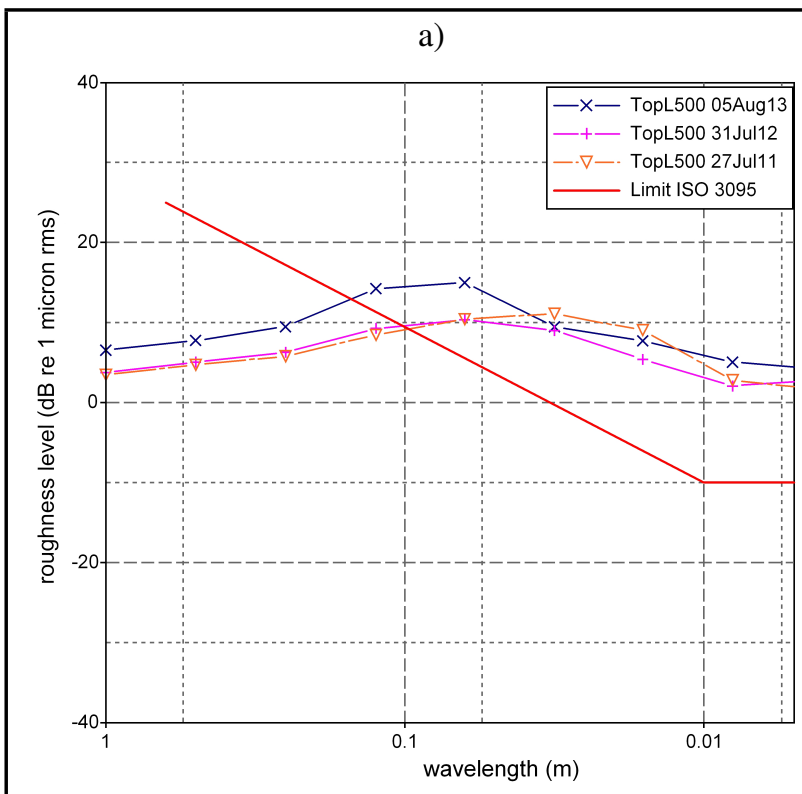

b)

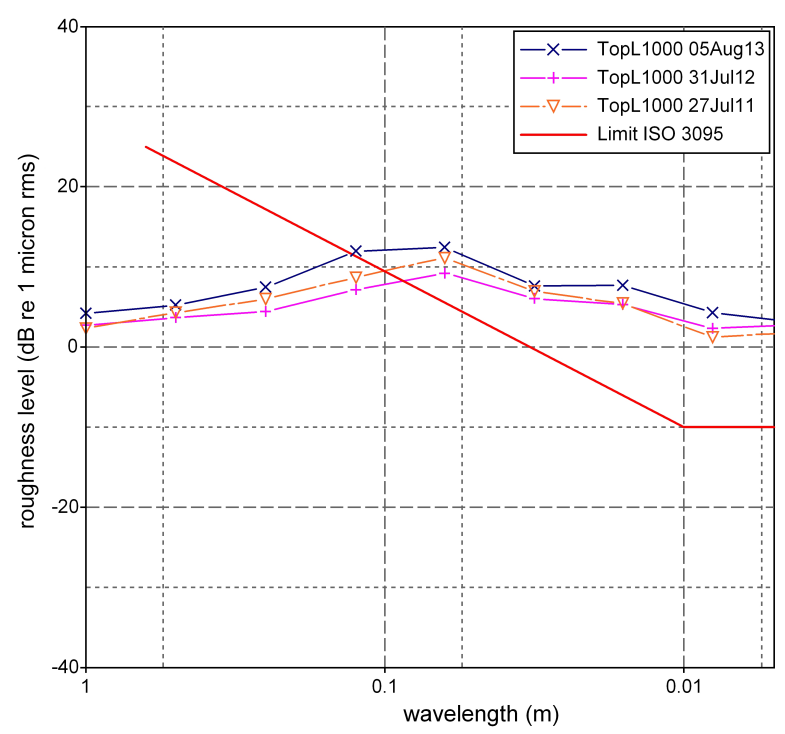

c)

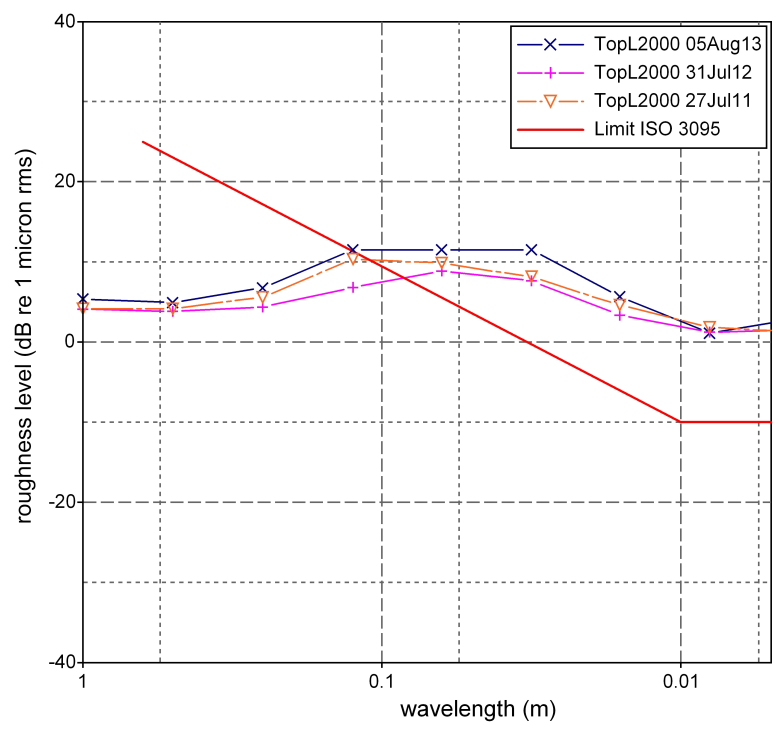

Figure 8. Roughness growth of low rail. a)

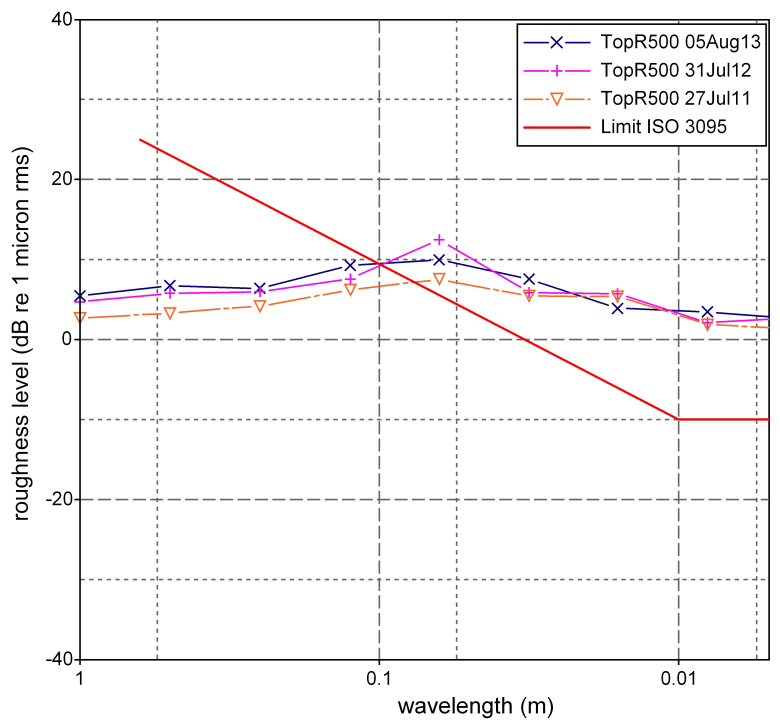

b)

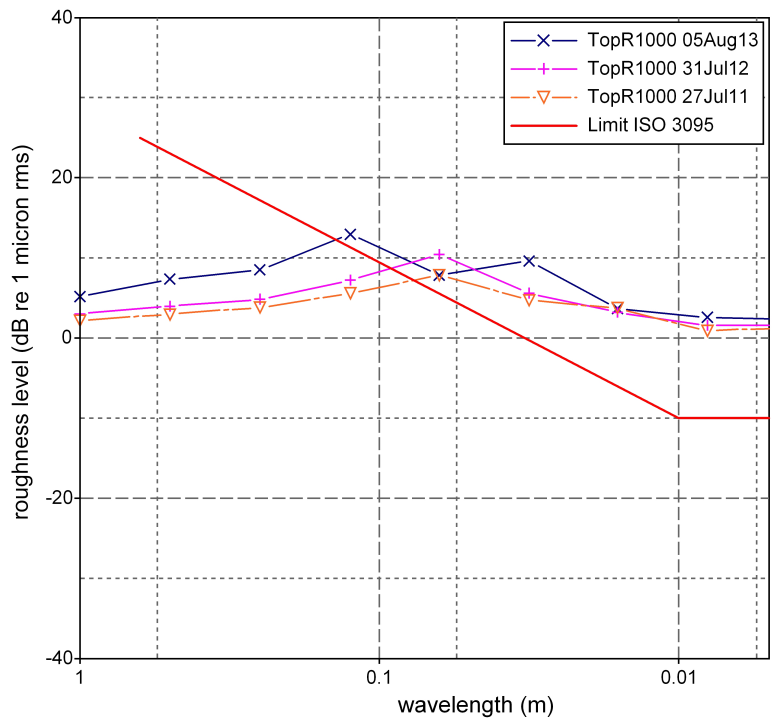

c)

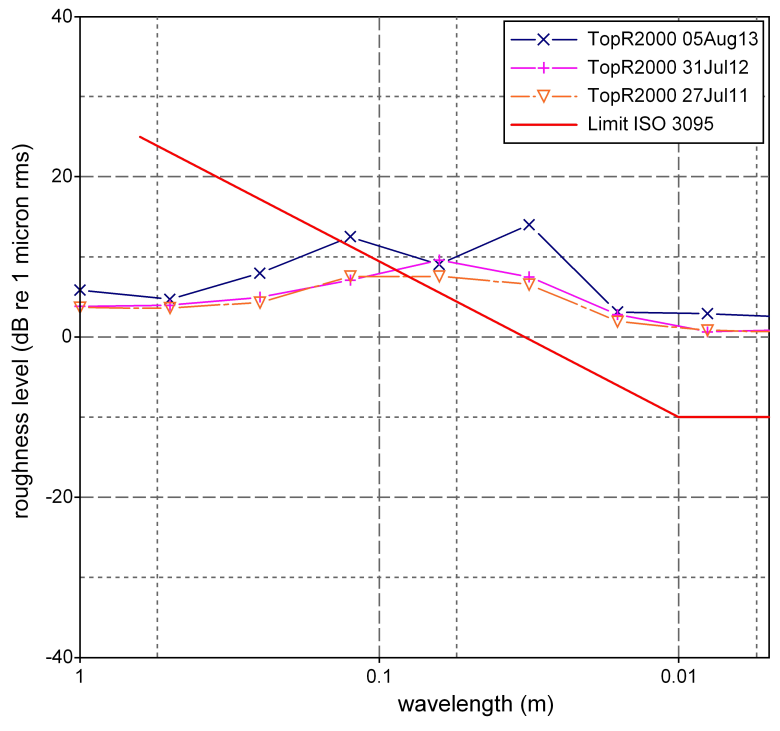

Figure 9. Roughness growth of high rail. 
Table 2. Track maintenance priority for rail corrugation defects (H: High; M: Medium; L: Low).

\begin{tabular}{||c|c|c|c||}
\hline $\begin{array}{c}\text { Feasible causes } \\
\text { to railway systems }\end{array}$ & $\begin{array}{c}\text { Operational } \\
\text { Risk }\end{array}$ & $\begin{array}{c}\text { Safety } \\
\text { Risk }\end{array}$ & $\begin{array}{c}\text { Priority } \\
\text { Ranking }\end{array}$ \\
\hline $\begin{array}{c}\text { Track damages } \\
\text { (cracked/broken components) }\end{array}$ & $\mathrm{H}$ & $\mathrm{H}$ & 1 \\
\hline $\begin{array}{c}\text { Train damages } \\
\text { (coupler failure, } \\
\text { loosen components) }\end{array}$ & $\mathrm{H}$ & $\mathrm{H}$ & 2 \\
\hline $\begin{array}{c}\text { Plastic deformation/lipping/tight } \\
\text { gauge/source to regenerate other } \\
\text { rail defects }\end{array}$ & $\mathrm{M}$ & $\mathrm{H}$ & 3 \\
\hline $\begin{array}{c}\text { Signal equipment failure } \\
\text { from vibrations }\end{array}$ & $\mathrm{M}$ & $\mathrm{M}$ & 4 \\
\hline $\begin{array}{c}\text { Ground-borne } \\
\text { vibrations }\end{array}$ & $\mathrm{M}$ & $\mathrm{M}$ & 5 \\
\hline $\begin{array}{c}\text { Poor ride } \\
\text { quality }\end{array}$ & $\mathrm{M}$ & $\mathrm{L}$ & 6 \\
\hline $\begin{array}{c}\text { Environmental } \\
\text { noise }\end{array}$ & $\mathrm{M}$ & $\mathrm{L}$ & 7 \\
\hline
\end{tabular}

tion with risk management, track engineers can prioritise track maintenance, in order to:

- Reduce noise and vibration spectra in urban area (wavelengths associated with natural frequencies of ground and built environments)

- Reduce potential damage to train and track components with respect to large corrugation amplitude

- Improve ride conform to passengers by smooth rail grinding (rail surface metal removal), and

- Predict track maintenance interval for specific locations, of which track and operational parameters induce severe corrugations.

\section{CONCLUSIONS}

Significant demand for rail asset management with physical constraints has resulted in an application of vehicle-track interaction for assessment and monitoring of rail assets. In practice, rail corrugations are firstly detected by train drivers and track inspectors. The locations of mild to severe corrugations are often known in advance by infrastructure managers. However, monitoring the rail surface defects to prioritise maintenance frequency and tasks are often inadequate because detailed inspections (using CAT or track measurement trolley) require track closure and safety management, which are time and resources-consuming. This paper demonstrates an application of vibration-based data obtained from an inspection vehicle to assist track maintenance engineers predicting severity overtime and controlling rail corrugation growth on sharp curves. A case study using the inspection vehicle data on a selected track section with a very sharp curve radius was carried out as a demonstration.

This case study demonstrates that track engineers can use the inspection vehicle to monitor rail corrugation growth. Top 500 is found to be a stable data set, which could be used for corrugation monitoring. The efficiency of track maintenance can be improved by using such application integrated with risk management framework. The improvement will also enhance ride comfort and quality of lives for railway neighbours. The data analytics also suggest area of improvement. Higher quality and sampling rate of data collection are essential to the improvement of accuracy of rail roughness back-calculation at a micro-meter level. Automated inspection system, condition monitoring, and trend analysis are among the demanding and important future research topics related to railway structural monitoring and maintenance.

\section{ACKNOWLEDGEMENTS}

The author is grateful to RailCorp and Asset Standards Authority, transport for NSW, for the permission to publish the data. Very positive and constructive comments from all six reviewers are highly appreciated. The author also wishes to thank Australian Government's Department of Innovation for supporting his Endeavour Executive Fellowships at Department of Civil and Environmental Engineering, Massachusetts Institute of Technology, at John F. Kennedy School of Government, Harvard University, Cambridge MA, USA, and at Railway Mechanics Centre, Chalmers University of Technology, Gothenburg, Sweden. The author is very grateful for the financial support from European Commission for H2020-MSCARISE Project No. 691135 "RISEN: Rail Infrastructure Systems Engineering Network", and for H2020-S2R Project No. 730849 "S-Code: Switch and Crossing Optimal Design and Evaluation".

\section{REFERENCES}

1 Bellette, P. A., and Meehan, P.A., Users guide to accelerometer based corrugation estimator software, RailCRC Report 2011/08, Brisbane, Australia, (2011).

2 Chen, H., Fukagai, S., Sone, Y., Ban, T., and Namura, A. Assessment of lubricant applied to wheel/rail interface in curves, Wear, 314 (1-2), 228-235, (2013). https://dx.doi.org/10.1016/j.wear.2013.12.006

3 Daniel, W. J. T., Pal, S., and Farjoo, M., Rail squats: progress in understanding the Australian experience, Proceedings of the Institution of Mechanical Engineers Part F: Journal of Rail and Rapid Transit, 227 (5), 481-492, (2013). https://dx.doi.org/10.1177/0954409713500950

4 Dhanasekar, M., Remennikov, A. M., Kaewunruen, S., and Zong, N, Advances in RailTrack Infrastructure Research and Practice, Special Issue in Electronic Journal of Structural Engineering, 13 (1), 97, (2013).

5 Grassie, S. L., Saxon, M. J., and Smith, J. D. Measurement of longitudinal rail irregularities and criteria for acceptable grinding, Journal of Sound and Vibration, 227 (5), 949964, (1999). https://dx.doi.org/10.1006/jsvi.1999.2980

6 Grassie, S. L. Rail irregularities, corrugation and acoustic roughness: characteristics, significance, and effect of reprofiling, Proceedings of the Institution of Mechanical Engineers Part F Journal of Rail and Rapid Transit, 226 (5), 542-557, (2012). https://dx.doi.org/10.1177/0954409712443492

7 International Standards Organisation, EN ISO 3095:2005 Railway applications - acoustics measurement emitted by railbound vehicles, France, (2005). 
8 Ishida, M., Moto, T., and Takikawa, M. The effect of lateral creepage force on rail corrugation on low rail at sharp curves, Wear, 253 (1), 173-177, (2002). https://dx.doi.org/10.1016/S0043- 1648(02)00096-0

9 Kaewunruen, S. Effectiveness of using elastomeric pads to mitigate impact vibration at an urban turnout crossing, in Maeda et al. (Eds.) Noise and Vibration Mitigation for Rail Transportation Systems, Springer, 357-365, (2012). https://dx.doi.org/10.1007/978-4- 431-53927-8_42

10 Kaewunruen, S. Acoustic and dynamic characteristics of a complex urban turnout using fibre-reinforced foamed urethane (FFU) bearers, Proceedings of 2013 International Workshop on Railway Noise, 9th-13th September 2013, Uddevalla, Sweden.

11 Kaewunruen, S. Monitoring structural deterioration of railway turnout systems via dynamic wheel/rail interaction, Case Studies in Nondestructive Testing and Evaluation, 1 (1), 19-24, 2014. https://dx.doi.org/10.1016/j.csndt.2014.03.004

12 Kaewunruen, S. Monitoring in-service performance of fibre-reinforced foamed urethane sleepers/bearers in railway urban turnout systems, Structural Monitoring and Maintenance - An international Journal, 1 (1), 131-157, (2014). https://dx.doi.org/10.12989/smm.2014.1.1.131

13 Kaewunruen, S. and Remennikov, A.M. Dynamic properties of railway track and its components: recent findings and future research direction, Insight: Non-Destructive Testing and Condition Monitoring, 52 (1), 20-22, (2010). https://dx.doi.org/10.1784/insi.2010.52.1.20

14 Kaewunruen, S. and Remennikov, A. M. Current state of practice in railway track vibration isolation: an Australian overview, Australian Journal of Civil Engineering, 14 (1), 63-71, (2016). https://dx.doi.org/10.1080/14488353.2015.1116364

15 Kaewunruen, S. and Ishida, M. In situ monitoring of rail squats in three dimensions using ultrasonic technique, Experimental Techniques, in press, (2015). https://dx.doi.org/10.1111/ext.12171

16 Kaewunruen, S., Remennikov, A. M., and Murray, M. H., Greener \& Leaner: Unleashing the capacity of railroad concrete ties, ASCE Journal Transportation Engineering, 137 (4), 241-247, (2011). https://dx.doi.org/10.1061/(ASCE)TE.1943-5436.0000215

17 Meehan, P. A., Bellette, P. A., and Horwood, R. J. 'Does god play dice with corrugations?': Environmental effects on growth, Wear, 314 (1-2), 254-260, (2014). https://dx.doi.org/10.1016/j.wear.2013.11.027

18 Pal, S., Daniel, W. J. T., and Farjoo, M. Early stages of rail squats formation and the role of a white etching layer, International Journal of Fatigue, 52 (1), 144-156, (2013). https://dx.doi.org/10.1016/j.ijfatigue.2013.02.016

19 Pang, S., Zhao, W., Dong, H., Peng, W., and Chen, J. The city rail safety detection sensor network platform using online track detection, in Lecture Notes in Electrical Engineering, 288 (1), 349-353, (2014) https://dx.doi.org/10.1007/978-3-642-53751-6_37

20 Pacific Real Time ROAMES Operator Training Manuals, Sydney, Australia, (2009).

21 Remennikov, A. M. and Kaewunruen, S. A review of loading conditions for railway track structures due to train and track vertical interaction, Structural Control and Health Monitoring, 15 (2), 207-234, (2008). https://dx.doi.org/10.1002/stc.227

22 Remennikov, A. M., Murray, M. H., and Kaewunruen, S. Reliability based conversion of a structural design code for prestressed concrete sleepers, Proceedings of the Institution of Mechanical Engineers Part F: Journal of Rail and Rapid Transit, 226 (2), 155-173, (2012). https://dx.doi.org/10.1177/0954409711418754

23 RailCorp Rolling Stock Engineering: Minimum Operating Standards for Rolling Stocks, Sydney, Australia, (2013).

24 RailCorp Engineering Standards: Track Engineering, Sydney, Australia, (2013).

25 Sato, Y., Matsumoto, A., and Knothe, K. Review on rail corrugation studies, Wear, 253 (1), 130-139, (2002). https://dx.doi.org/10.1016/S0043-1648(02)00092-3

26 Suda, Y., Hanawa, M., Okumura, M., and Iwasa, T. Study on rail corrugation in sharp curves of commuter line, Wear, 253 (1), 193-198, (2002). https://dx.doi.org/10.1016/S0043-1648(02)00099-6

27 Sun, Y. Q., Cole, C., McClanachan, M., Wilson, A., Kaewunruen S., and Kerr M. Rail short-wavelength irregularity identification based on wheel-rail impact response measurements and simulations, in Z Geng (ed.) Proceedings : 9th International Heavy Haul Conference (IHHC 2009), Shanghai, China, 22nd-24th June, China, (2009), Railway Publishing House, Beijing, China.

28 Sun, Y. Q. Final technical report of Railcar Project No. 3.104 Rail corrugations, Australian Cooperative Research Center for Railway Innovation, Brisbane, Australia, (2012).

29 Thompson, D. J. Railway Noise and Vibration, Elsevier, Amsterdam, The Netherlands, (2010).

30 Torstensson P. T. Rail corrugation growth on curves, $\mathrm{PhD}$ Thesis. Chalmers University of Technology, Gotenburg, Sweden, (2012).

31 Torstensson, P. T. and Schilke, M. Rail corrugation growth on small radius curves - measurements and validation of a numerical prediction model, Wear, 303 (1-2), 381-396, (2013). https://dx.doi.org/10.1016/j.wear.2013.03.029

32 Wang, H. G., Xiao, P. H. Analysis of influence factors in rail corrugation on sharp curve of metro, Railway Standard Design, (2013). 